\title{
THE ROMA ON THE LABOR MARKET \\ - TRENDS, PROBLEMS AND PERSPECTIVES \\ (A CASE STUDY OF HARMAN MAHALA - PLOVDIV, BULGARIA)
}

DOI: http://dx.doi.org/10.18509/GBP.2020.42

UDC: $331.5(497.234:=214.58)$

\author{
Aleksandra Ravnachka \\ Boris Kazakov \\ National Institute of Geophysics, Geodesy and Geography, \\ Bulgarian Academy of Sciences, Bulgaria
}

\begin{abstract}
Over the past two decades the issues of social integration of Roma in Bulgaria, including their participation in the labor market, have been of growing importance to the society due to the growing number of Roma people in the country. Problems related to employment, type of income and reduction of unemployment benefits are becoming more and more urgent. The study represents the general overall situation of the Roma on the labor market in Bulgaria on the one hand and the results from a survey at a low territorial level - a Roma quarter - which makes it possible to reveal in detail the specifics of the process of Roma integration and their way of coping with the changes in the labor market. The specifics features of the various Roma communities in Bulgaria should be taken into account in the process of strategic and planning documents development, in order to achieve their main objective - to reduce regional and intra-regional disparities and social inequality.

The scientific research on Roma participation in the labor market, the policies of their integration and the accompanying problems are insufficient in Bulgaria. Most of the research is general, at national level. The main reason for this is the lack of information and limitations in studying the labor force and the labor market at local level, and especially on the basis of ethnicity. The paper presents the results from a survey among 500 residents of the Roma quarter of Harman Mahala, Plovdiv, based on questionnaires and expert interviews. The study aims to reveal the participation of the Roma in the labor market in terms of scale, types of employment, attitudes towards work and last but not least - the obstacles hampering the Roma social inclusion.
\end{abstract}

Keywords: Roma population, labor market, Harman Mahala, Plovdiv

\section{INTRODUCTION}

The Roma are the most vulnerable ethnic group in Bulgaria, featured by a low social status and a low labor market participation. The social integration of that ethnic community through increased participation in the economy of the country is crucial for raising the Roma's standard of living and improving their overall social realization. The attitude of the macro-society towards the Roma helps creating a separate social category with common problems: poverty, marginalization, segregation, poor access to social services, exclusion from the practice of active citizenship, intolerance, discrimination, prejudice, negative stereotypes, etc. Employment plays an important role as a tool of social inclusion since it provides opportunities for interaction, thereby reinforcing social cohesion. 
The problems and challenges facing the participation of the Roma in the labor market and the policy pursued for their integration have been the subject of scientific and managerial interest in Bulgaria and in other European countries with a significant number or share of Roma. A rich regulatory framework has been created in the Bulgaria, including a number of strategies and plans, such as the National Strategy of the Republic of Bulgaria for Roma Integration (2012 - 2020), the Strategy for the Educational Integration of Children and Students from Ethnic Minorities, the National Action Plan: Decade of Roma Inclusion 2005-2015, all focused on the social and economic integration of the Roma people, including integration into the labor market. A large number of studies have been carried out and numerous national and European projects have been developed, most of them however - at national level. There are few regional studies and one of the main reasons for this is the lack of sufficient information. Studies at a lower territorial level or in specific Roma neighborhoods / quarters allow exploring and revealing of the specificities of the Roma - features which need to be taken into account in the development of strategic and planning documents - the main tools for reducing regional and intra-regional disparities, and limiting social and economic segregation [9].

A number of the authors have recently worked on the problems of employment, unemployment, the low qualification of the Roma and their social integration into the Bulgarian societies [4] [5] [6] [8] [9] [11].

\section{INFORMATION SOURCES AND METHODOLOGY OF THE STUDY}

For the purposes of this study, the following sources of information were used:

- Literary sources including scientific publications and reports, summaries of strategic and planning documents, data, results and analyses from the World Bank reports, online sources, etc. [7] [13] [14] [15] [16] [17] [18] [19] [20].

- 2011 official census data and data on economic activity of the population provided by the National Statistical Institute of Bulgaria [12].

- Sociological surveys conducted in the Harman Mahala quarter of the city of Plovdiv, Bulgaria. A total of 500 residents aged 18+ (out of 1790 residents in total [1] were included in the survey, based on a master questionnaire of 133 questions, grouped in several sections, aimed at establishing demographic, social and other characteristics of the respondents and their living environment. Thirteen questions included in the questionnaire distributed among the respondents from the target community deal with labour and economic activity. Approximately $96 \%$ of the respondents are of Muslim religion and identify themselves as Millet or Turks), while the surrounding population (the Bulgarian macro-society) regards them as Roma or Turkish Roma.

- Several expert interviews have been conducted with representatives of the following institutions: The Housing and Social Activities Division of the North Administrative Region -Municipality of Plovdiv, the Social Assistance Agency, the Social Policy Division of Plovdiv Municipality, the Bulgarian Red Cross, the Regional Administration of Plovdiv Region, the Labour Office in the city of Plovdiv. The professional opinions of the interviewed experts were taken into account in order to facilitate some conclusions regarding the integration of the Roma people into the labour market of Bulgaria.

The main difficulties encountered during the study were related to the fact that the labour force and the labour market data in the country do not observe the ethnicity of the population. Therefore, various data from national and international reports and surveys 
were used in order to establish certain values regarding the employment / unemployment rates among Roma in Bulgaria, as well as their overall economic activity status.

\section{GROPUS OF POPULATION BY ECONOMIC ACTIVITY IN BULGARIA - A BRIEF OVERVIEW}

The economic activity of the population and its participation in the labour market in Bulgaria is characterized by several major groups of people:

Working population, which can be divided into:

- Employed workers - those represent the largest group of economically active persons - as it normally is in any country; in Bulgaria the number of employed workers as of the beginning of 2019 is 2785000 people (out of an estimated total population of 7 000039 people, out of which 5995194 aged 15+ years);

- Employers - those are the persons who are economically active by hiring personnel for their businesses, regardless of the size and ownership (private or state sector); the number of employers in Bulgaria as of 2019 is 177 000;

- Self-employed workers - some 227000 Bulgarian citizens are considered selfemployed, meaning they run various economic activities and businesses on their own.

- Unpaid household workers - this is a specific group of working persons, since they exercise certain labour activities and therefore are a part of the working population, but do not actually contribute directly to the economy since their labour does not involve monetary income or payment (and similar to other unofficial forms of labour, are not subject to taxation). This is the smallest group of working population in Bulgaria (24 000 people as of 2019).

- Working retired - although not expected to work, hundreds of thousands of pensioners in Bulgaria (as in many other countries) continue working after retirement, mostly in order to provide some additional income. The number of the working pensioners in the country varies according to the various sources from 150000 [7] to 318000 [3], although the different sources cite the same institution as a data source - the National Insurance Institute of Bulgaria.

Not working population, which can be divided into:

- Unemployed - although considered part of the economically active, the unemployed people cannot be considered a part of the working population. That being said, it does not always mean that all unemployed people do not actually work, but if they do, that happens in a semi-legal or illegal mode (in which case such persons get both social welfare for unemployed and payment). The unemployment rate in Bulgaria as of the beginning of 2019, similar to the majority of the EU countries is very low $-4.4 \%$ or 142000 people as of the first half of 2019. Low unemployment rates, however, should not be interpreted one-sidedly, because they can be a sign of macroeconomic processes which are not necessarily so positive.

- Retired unemployed - naturally, all retired people get some sort of pension and therefore those are not expected to have to work, thus representing the largest group of the not-working population in any country. The vast majority of the retired people in Bulgaria fall into that group (some 2 million people);

- Economically inactive - the economically inactive people are the second largest group of people in the country right after the employed workers with almost equal number of representatives. That group includes various subgroups, among which the most significant is the group of persons who are not willing to work (some 2.5 million people total). It should be noted, however, that the majority of those persons declare 
their "advanced age" as a reason not to work, while some 430000 people are in training (formal or vocational). The remainder of the people not willing to work comprises two almost equal subgroups of persons - those who are sick and / or invalids -221000 and those who are not willing to work for personal or family reasons -273000 .

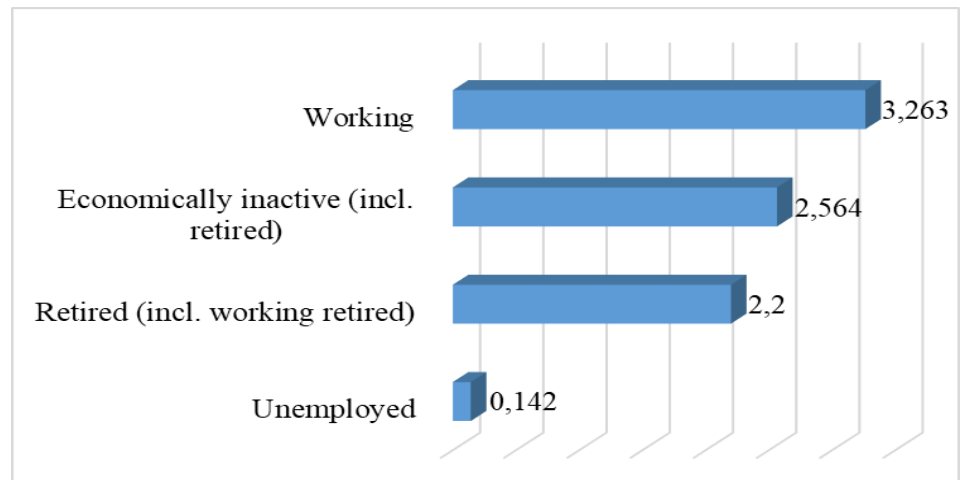

Figure 1: Number of people by economic activity (million people) in Bulgaria as of the beginning of 2019

Source: Author, based on National Statistical Institute (NSI) data (https://www.nsi.bg)

The high number of economically inactive people in the Bulgaria (as a share of the total population aged 15+) is mostly a result of the deteriorated age structure of the country's population, combined with a significant number of people in training (university students, etc.) and people who are not considered unemployed, but are not willing to work for various reasons, such as sickness, personal and family reasons.

\section{BASIC ECONOMIC ACTIVITY FEATURES OF THE ROMA IN BULGARIA}

The analysis of the participation of the Roma in the labour market at national and regional level shows that the main features characterizing the situation of the Roma are their low levels of employment, high unemployment rate, high share of de facto economically inactive, significant involvement in grey economy activities, high share of Roma population below the poverty line compared to the Bulgarian ethnic group and the Turkish ethnic group in the country. As a result, the "at-risk-of-poverty" rate of Roma in Bulgaria (as of 2014) was $86 \%$, while for the total population it was $22 \%$ (Second European Union Minorities and Discrimination Survey. Roma - Selected findings, 2016).

According to a 2017 report on the Roma in Bulgaria and Hungary [8], half of the Bulgarian Roma included in the survey declared they were unemployed, while those who declared any employment were often temporarily and not permanently employed (Fig. 3) Another survey by the European Union Agency for Fundamental Rights (FRA) states that almost two-thirds (61\%) of young Roma in Bulgaria (aged 16-24) are neither in work nor in education or training (NEET), compared to $22 \%$ for the non-Roma. (Transition from education to employment of young Roma in nine EU Member States, 2018). This clearly shows the uneven start which young Roma have in comparison to the non-Roma in the beginning of their work life and labour realization. Of course, the main reason for that is the lower education attainment of young Roma people, which is proven by the figures cited by the Institute of Market Economy in Bulgaria, which show that ethnicity has almost no relevance when it comes to the correlation between low education level 
and poverty $-58 \%$ of the working Bulgarians, $59 \%$ of the Roma and $42 \%$ of the ethnic Turks with only primary or no education are poor [8].

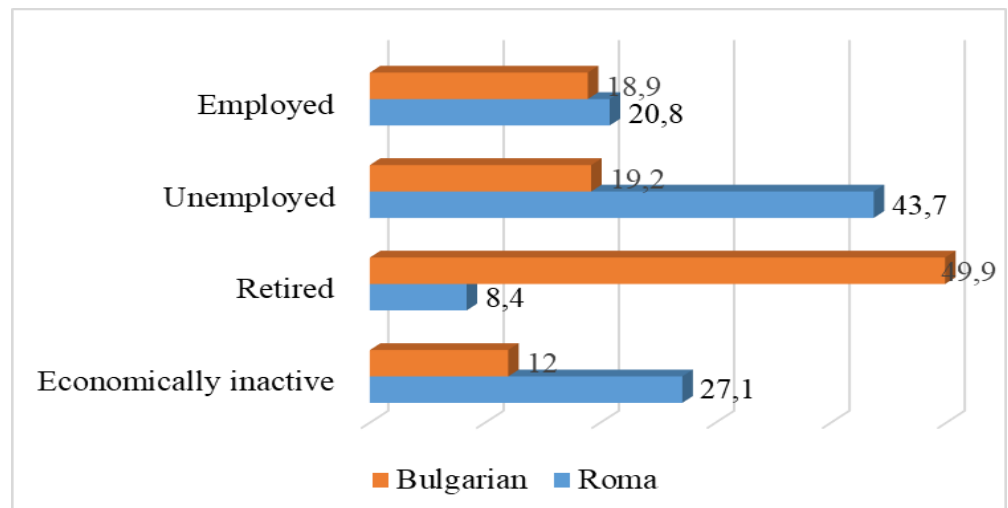

Figure 2: Share of population (\%) below the poverty line by economic activity and ethnicity in Bulgaria Source: Author, based on NSI data cited by the Institute of Market Economy in Bulgaria (https://ime.bg/bg/articles/nsi-povdiga-zavesata-bednost-i-etnieska-prinadlejnost/)

According to a study conducted by the Open Society Institute (2014) at national and local level, the majority of the working Roma are employed workers, and a very small proportion are engaged in their own businesses (1.6\% of all working Roma). In our view, the development of entrepreneurship among Roma would lead to an increase in employment among them and should become a priority of the policies and measures implemented to integrate and the Bulgarian Roma population into the labour market. According to the same study the employment of Roma in the primary labour market through various programs has dropped twice compared to 2001. The reasons for this are not only the intensified emigration of Roma to Western Europe, but also the employment of Roma in various forms of informal economy, as well as psychological factors, and last but not least - the selective attitude of the Roma towards the work and the salary offered.

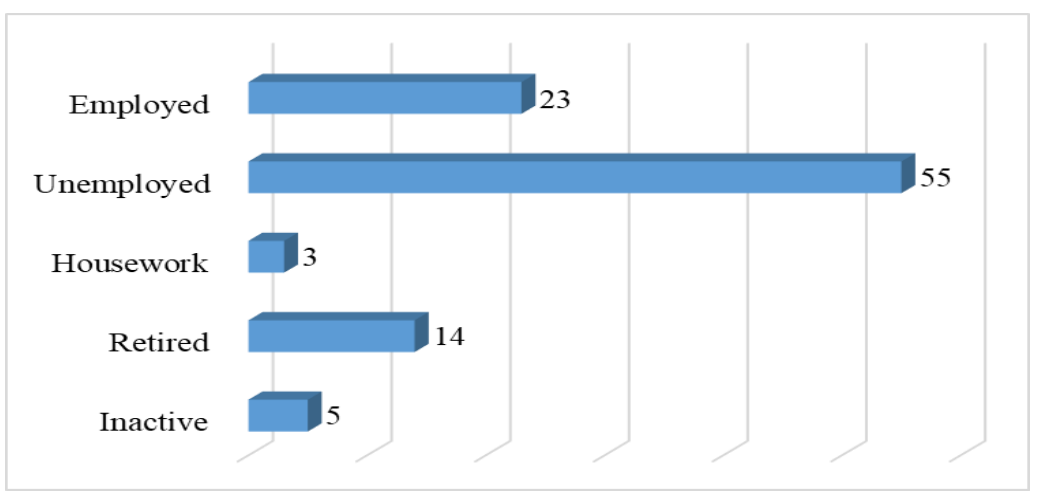

Figure 3: Self-declared current economic activity status of the Roma in Bulgaria (\%) Source: Author's adaptation based on Mesing, V., Z. Arendas, 2017

Since 2001, and especially since Bulgaria's accession to the EU, the proportion of Roma temporarily working abroad has increased dramatically. According to previous research [10], 18\% of Roma households in Bulgaria have a member or members of the household who had worked abroad in the last five years. In some Roma quarters, about $40 \%$ of the Roma households have at least one member working abroad. Over $50 \%$ of the respondents indicated that they had a member of the household who had worked or are 
currently working abroad, mostly in Germany, England and France. A trend which fully applies for the studied community from Harman Mahala quarter of the city of Plovdiv.

\section{THE CASE STUDY OF HARMAN MAHALA QUARTER, PLOVDIV, BULGARIA}

Harman Mahala quarter is the smallest of all four Roma quarters in the city of Plovdiv, Bulgaria. Its population is estimated to be some 1800 people [1], while the vast majority of the residents declare themselves as Millet (or Turks), belonging to the Muslim religion. A small part of the residents declare themselves as Roma of the Burgudzhii group, while all residents of the quarter are regarded by the surrounding population simply as Gypsies or Roma.

The current case study shows large differences in the participation of Roma in the labour market at national and local level, in terms of the diversity of indicators for measuring, analysing and evaluating Roma employment. Employment among respondents living in the studied community can be defined as relatively high $-57 \%$ of the respondents work, $51 \%$ of them - full-time, and $58 \%$ of those - on a contract. It should be noted that the majority of the employed respondents found jobs through relatives $(43.2 \%)$, friends (35.6\%) and neighbours (18.2\%), while the share of those who found a job through various employment programs and the Labour Office is extremely low $-0.3 \%$. This is a clear representation of the low reliance of the community members on the state institutions when it comes to looking for a job.

Educational attainment is one of the main factors influencing the labour market realization. The low education level of the Roma in general and in the surveyed community, together with the lack of qualification of the majority of the respondents predetermine their low participation in the labour market and their low paid and lowskilled jobs, mostly as janitors (20\% of the employed respondents), employment in industry and manufacturing (17\%), construction (16.5\%), landscaping (12\%), drivers (including illegal taxi drivers $-9 \%$ ), etc.

This not only determines their low social status and, but also affects the children's educational attitude and value system, including the working attitudes of adolescents (the survey results show that a relatively small proportion of the Roma students want to get a university degree, while approximately $70 \%$ of them declare their willingness to work jobs requiring a lower education - mainly in the services sector (hairdressers, barbers, beauticians, cooks, restauranteurs, tailors, drivers, car mechanics, builders and musicians. The share of students who prefer to work in the future as lawyers, doctors, police officers or firefighters is relatively low.

Some $38 \%$ of the respondents declare that they are unemployed. The significance of education can also be seen from the current project survey results on reasons for unemployment - almost half of the unemployed respondents (46\%) declare lack of sufficient (or any) education and lack of qualification as a reason for unemployment. A disturbing $22 \%$ of the respondents, however, declare as a main reason for unemployment "ethnicity and discrimination", which speaks of the deep issues Bulgarian society traditionally has had in terms of "acceptance" of the Roma people in general. Low wages are considered a main reason for unemployment (or rather - unwillingness to be employed) by $17 \%$ of the respondents, while some $6 \%$ see their unemployment as a result of their low conduct of Bulgarian language. 
The structure of income is another important indicator of the position of Roma on the labour market in terms of reliance on paid jobs on a work contract. Regardless of the fact that it may seem surprising to many representatives of the Bulgarian macro-society, the main source of income of the surveyed community respondents is the wage. However, less than $1 / 3$ rd of the respondents actually rely on wages as main source of income (Fig. 4), while the rest declare as a main income source pensions (18\%), followed by unspecified income from return migration, child allowances, sidewalk trade, social benefits, etc. In addition, half of the respondents also rely on financial support from relatives working abroad. As a result, most of the surveyed Roma live on incomes who in total exceed the national poverty line (BGN 348 or some 174 euros per month, since mid-2019) - the respondents declared the following scales of income: $81 \%$ - over BGN 500 (or $€ 250$ ), while only 18\% declared an income between BGN 200 and BGN 500 $(€ 100-250$ respectively).

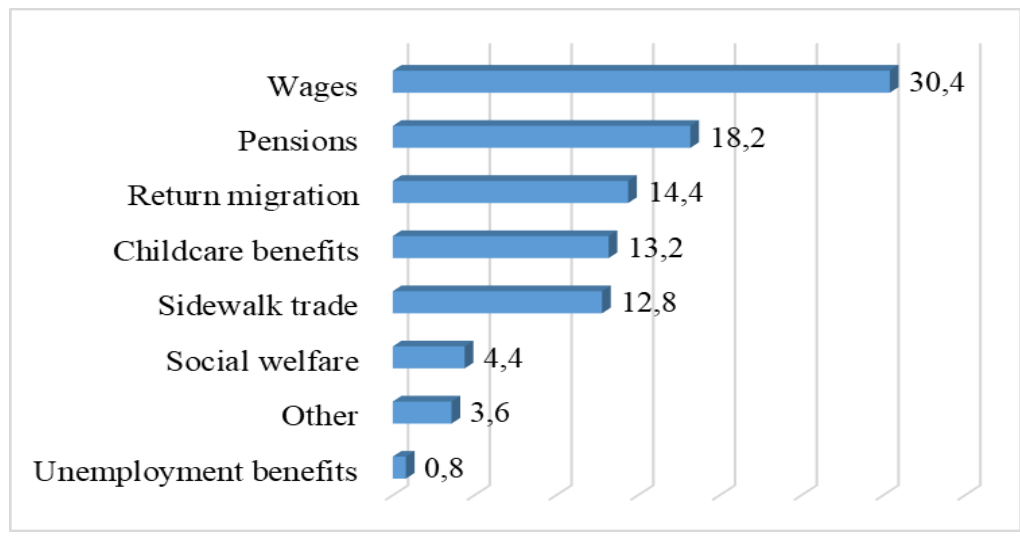

Figure 4: Main source of income for the residents of Harman Mahala quarter, Plovdiv (\% of respondents).

Source: Author, based on project survey results

Unemployment, lack of sufficient income, poverty and the pursuit of a better life all determine the intensified emigration of Roma population. In fact, $62.3 \%$ of the respondents from the surveyed community in Plovdiv indicate that the main reasons why they would emigrate are the high unemployment rate among the Roma in Bulgaria and the low standard of living they have in the country. The share of Roma pointing out other main reasons for emigration such as crime, social insecurity (9.6\%) and religious intolerance $(3.2 \%)$ is relatively low.

\section{THE EXPERTS' OPINION ON THE MATTERS OF ROMA ON THE LABOUR MARKET AND SOCIAL BENEFITS RELIANCE}

According to municipality officials, the business in Plovdiv is ethnically tolerant and is actually in constant demand of workers, including less qualified. The business requires employees from the Labour Office with the only requirement for those future employees to be at least literate and willing to undergo some training. Therefore, few people who are actively looking for work are actually unable to find one - most of them do. The business is approaching the Labour Office with the words: "provide us workers"! Some ten years ago the demand was much lower, while nowadays there are many vacant jobs and employers are ready to hire low-skilled workers and train them. Roma, therefore, should not be regarded as a burden to the society, but rather as an economic potential - no the 
need to be highly educated to find some social realization - education is only necessary if you want to improve your skills for a better job.

According to Social Assistance Agency experts from the city of Plovdiv, the Roma exhibit a clear selective attitude towards the job and the salary which is offered. Another common issue is that a certain number of Roma are employed in the grey economy, while still registered in the Labour Office as unemployed not to actually get a job, but only to get social welfare for unemployed - a common practice among representatives of all ethnic communities in the country, not just the Roma. Since the criteria for social welfare in Bulgaria are extremely high, while in the same time the welfare itself is insignificant, the Roma do not actually rely on social welfare and even they receive none, which is not a reason for them to start looking for a job. Truth be told, a small number of Roma people actually apply for social welfare because this way they also get a health insurance and not because they can rely on social welfare to support themselves. The fact is, the Roma rely less and less on social benefits and the number of applicants for social assistance in 2017 was significantly lower than in previous years (the number of people on a monthly social welfare in Plovdiv, regardless of their ethnicity, is extremely low - just 170 people in the entire city). Apart from the extremely strict criteria for eligibility for social welfare, the Roma in particular face serious difficulties related to current address registration - a necessary condition for applying for social assistance. This is due to the fact that most of the Roma live in illegal housing in the so-called ghettoized urban structures [2] which is a major problem when it comes to providing a current address, and hence - for submitting applications for social welfare. In addition, experts state that the vast majority of the Roma applying for social benefits, including benefits for raising children, are practically illiterate and do not speak Bulgarian, regardless of their formal educational attainment. Therefore, such Roma are often accompanied by elderly relatives, who were educated before 1990 (during the communist era in Bulgaria), to help them fill in the papers needed for social welfare application.

Another main factor for lowered interest in social benefits reliance is the increased obtaining of income from informal economic activities, obtaining financial aid from relatives working abroad and afterall - the low level of social benefits in Bulgaria in general, unlike in other countries. For example the majority of the Roma from Harman Mahala quarter moved to Germany because of the better social assistance $-€ 380$ is the monthly allowance for raising a child, compared to $€ 20$ for 1 child and $€ 45$ for 2 children in Bulgaria. The high level of involvement in "grey" or "hidden economy" activities adversely affects not only the labour market but also the process of integration into other elements of the social sphere, such as access to health care services which are guaranteed by health insurance.

According to a municipality expert on the ethnic and social policy issues, the strict criteria for social welfare in the end affect much more the poor ethnic Bulgarians, rather than the Roma themselves - to whom those criteria are allegedly designed for, in order to "discipline" the Roma. The limitations of childcare support affect much more Bulgarian families with both parents working and having one kid, rather than Roma families. Roma families with 5-6 children are not well-regarded by the Roma themselves - such Roma families are marginalized within the Roma community itself. The restrictions, however, affect some "good families" who want to have more kids. Therefore, the Roma shouldn't be regarded as a burden to the social system or to the society in general, but rather as potential, even more so in a diminishing and aging nation such as the Bulgarian nation. Raising awareness among the Roma about the existing job opportunities and vocational 
training is crucial. The information campaigns should be held in the Roma community itself and thus become more accessible. The mediators have a positive role for the integration. Mediators should be in contact with both employers and the Roma community and inform both sides. Roma mediators play an important role in the implementation of the various programs and measures, educational and social initiatives that address the Roma population.

\section{CONCLUSION}

In spite of the higher employment rate among the Roma from Harman Mahala neighbourhood, low educational attainment and low qualification, together with the existing spatial segregation, the lack of motivation to work, etc., are all factors that predetermine low participation in the labour market. On the other hand the Roma are not really interested enough for the job opportunities which exist. The problems however are not one-sided - discrimination, although not apparent, exists and many employers refuse to employ Roma workers based on their ethnicity, which additionally limits the inclusion of Roma into the labour market. According to the above-mentioned FRA survey, just 31 $\%$ of the Roma in Bulgaria have experienced discrimination at work, while $69 \%$ of them felt discrimination while looking for work. The paradox is that the Bulgarian macrosociety only seemingly want the Roma to integrate, but on the other hand they don't really want them as part of the society. The Roma should be aware that apart from civil rights they also have responsibilities. Most of the Roma only demand, while their irresponsible civil conduct hardly ever is sanctioned. Positive examples of Roma labour behaviour should be offered to the Roma community itself, not only to the macro-society of ethnic Bulgarians, so as to play a positive role in the promotion of social integration and how it can benefit the Roma who have integrated in one way or another.

The Roma integration strategies, although backed up by EU or state financing, lack control on how the funds are spent - few people get obliged (some informal Roma leaders), while there are no actual results concerning the common Roma population. Some of the Roma NGOs enhance the solving of the problems by working along with the authorities. The local authorities must be granted rights to control the fund spending related to the implementation of "Roma projects", since many of the projects turn out fictive. There has been a positive trend in that aspect but with too insignificant results mostly depending on the specifics of the different Roma groups. Each policy should be designed by experts and not politicians, so as to assess the benefit for the whole nation, while public authorities should ensure that vocational training schemes targeted at the Roma, reflect their specific situation, as well as the labour market demand. (Poverty and employment..., 2014).

\section{Acknowledgments}

The study has been conducted within a project titled "Spatial segregation and its impact on the social integration of the Roma population in Harman Mahala, Plovdiv", funded by the National Scientific Research Fund of the Republic of Bulgaria, Grant No ДН15/7.

\section{REFERENCES}

[1] Asenov, K. (2017). Origination, spatial and cultural development of Harman Mahala doctoral thesis, "Paisii Hilendarski" University of Plovdiv, 2017 (in Bulgarian)

[2] Asenov, K. (2018). Anthropology of the "ghetto" - space and culture, "Studio 18", Plovdiv (in Bulgarian) 
[3] Beykova, E. (2019). The National Insurance Institute will recalculate the pensions of the working pensioners. (https://dariknews.bg/novini/bylgariia/noi-shte-preizchisliava-sluzhebnopensiite-na-raboteshtite-pensioneri-2164241) (in Bulgarian)

[4] Hyuseinov, B. (2014). Solving the socio-economic problems of the Roma in Bulgaria and in the EU countries, In: "The rise of nationalisms, Roma integration", Sofia, pp. 198-212), ISBN 978-619-160-322-0. (in Bulgarian)

[5] Hyuseinov, B. (2017). Education and employment - the main prerequisite for real integration of the Roma, In: "Problems of the Roma integration", Sofia, pp. 219-259), ISBN 978-954-298211-1(in Bulgarian)

[6] Ivanov, A. (2012). Quantifying the unquantifiable: Defining Roma population in quantitative surveys. Nasselenie Review 3(4), pp. 79-95

[7] Marova, Y. (2019). Nearly $150 \quad 000$ pensioners work (https://www.monitor.bg/bg/a/view/blizo-150-000-pensioneri-rabotjat-temata-160050)

[8] Mesing, V., Z. Arendas, (2017). Employment of Roma and potential of the state and business policies for inclusion of the Roma in the labour market. Budapest FRA EU MIDIS. (https://osis.bg/wp-content/uploads/2018/04/B2B_SoA-report_final_bg.pdf) (in Bulgarian)

[9] Pamporov, A. (2013). Special measures of the labour market in Bulgaria aiming at the assistance of the vulnerable groups on the labour market, NEUJOBS Working Paper (in Bulgarian)

[10] Ravnachka, A. (2017). Spatial disparities in the demand and supply of labour force in Blagoevgrad district (2001-2011) - doctoral thesis, Bulgarian Academy of Sciences, Sofia

[11] Tomova, I. Health and the Roma community - analysis of the situation in Europe, Preliminary national report, "Helth of the Roma" Foundation, ISBN: 978-84-692-5537-7 DP: GU-345/2009.

(http://www.gitanos.org/upload/87/58/BULGARIA-final-baja.pdf) (in Bulgarian)

[12] Zahariev, B., I. Yordanov (2014). Assessment of the inclusion of Roma in the labour market through general and specific for the target group measures and programs for employment, financed by the EU. Open Society Institute, Sofia.

[13] Census of the Population and the Housing Stock, 2011 (https://www.nsi.bg)

[14] Gender equality and the inclusion of Roma: the point of view of four Roma communities (2014), "Social Development" Unit of the World Bank for the region of Europe and Central Asia. (http://www.worldbank.org/content/dam/Worldbank/document/eca/Bulgaria/Roma_GenderBG.pdf) (in Bulgarian)

[15] Institute of Market Economy in Bulgaria (https://ime.bg/bg/articles/nsi-povdiga-zavesatabednost-i-etnieska-prinadlejnost/)

[16] National Strategy of the Republic of Bulgaria for Roma Integration (2012 - 2020) (https://www.president.bg/docs/1352306523.pdf) (in Bulgarian)

[17] National Statistical Institute of Bulgaria (https://www.nsi.bg)

[18] Poverty and employment: the state of the Roma in 11 EU member-states. (2014) (https://fra.europa.eu/sites/default/files/fra_uploads/fra-2014-roma-survey-dif-

employment_bg.pdf) (in Bulgarian)

[19] Second European Union Minorities and Discrimination Survey. Roma - Selected findings. (2016). (https://fra.europa.eu/sites/default/files/fra uploads/fra-2016-eu-minorities-surveyroma-selected-findings_en.pdf)

[20] Transition from education to employment of young Roma in nine EU Member States. (2018). (https://fra.europa.eu/sites/default/files/fra_uploads/fra-2018-eu-midis-ii-roma-transitioneducation-employment_en.pdf). 